\title{
THE PROBLEM OF OBESITY IN ANAESTHESIA FOR ABDOMINAL SURGERY
}

\author{
Alan B. Noble, M.D.
}

Apart FROM the technical inconvenience associated with the administration of an anaesthetic to an obese patient, certain physiological problems are encountered. We shall consider the very obese; because this state represents the culmination of factors resulting in the complete picture.

Certain eases of advanced obesity with its concomitant features of somnolence, twitching, periodic respiration, cyanosis, secondary polycythemia and chronic cor pulmonale have been labelled by Burwell ${ }^{1}$ as the Pickwickian Syndrome. This is an unfortunate reflection on our old friend Mr. Pickwick, who although plump, was physically and mentally agile. The actual allusion is to $\mathrm{Mr}$. Wardle's boy Joe, who was very fat. We assume that the resultant hypoventilation caused him to sleep a great deal of the time, except when contemplating or consuming food.

It is evident that the chronic respiratory insufficiency that disables the very fat patient does not usually commence with inherent pulmonary pathology. It is the result of impairment of the chest bellows. This function-so important in anaesthesia-refers to the co-ordinated mobility of the chest wall, diaphragm, and abdominal contents during respiration. The restrictive effects of ankylosing spondylitis and kyphoscoliosis impair the function of the chest bellows. A similar effect occurs in obesity.

The obese patient is embarrassed by an increase in the non-elastic resistance of the chest wall. The diaphragm is forced upwards by the increased volume of the abdominal contents with its contained fat. In addition the increased weight of the abdominal panniculus is more restrictive when the patient is supine. We have all observed that these patients have poor thoracic mobility while breathing spontaneously under anaesthesia, and their respirations are predominantly diaphragmatic.

Some four years ago Burwell and associates ${ }^{1}$ published an illuminating study of the effects of obesity on one patient. Estimations of lung volumes were made on an extremely fat man before and after reduction in weight by diet (see Tables I and II and Fig. 1).

TABLE I

Changes in One Patient Resulting from Dietary Weight loss over a Period of Three Weeks (From BurWell ${ }^{1}$ )

\begin{tabular}{lcc} 
& Before & After \\
\hline Weight, kg. & 121.4 & 103.6 \\
Arterial $\mathrm{O}_{2}$ saturation, \% & 80 & 98 \\
Arterial $\mathrm{pCO}_{2}, \mathrm{~mm} . \mathrm{Hg}$ & 73 & 37 \\
Arterial $\mathrm{pO}_{2, \mathrm{~mm} . \mathrm{Hg}}$ & 52 & 110 \\
Maximum breathing capacity, L./min. & 41.5 & 133 \\
\hline
\end{tabular}

'Department of Anaesthesia, Royal Victoria Hospital, Montreal. 

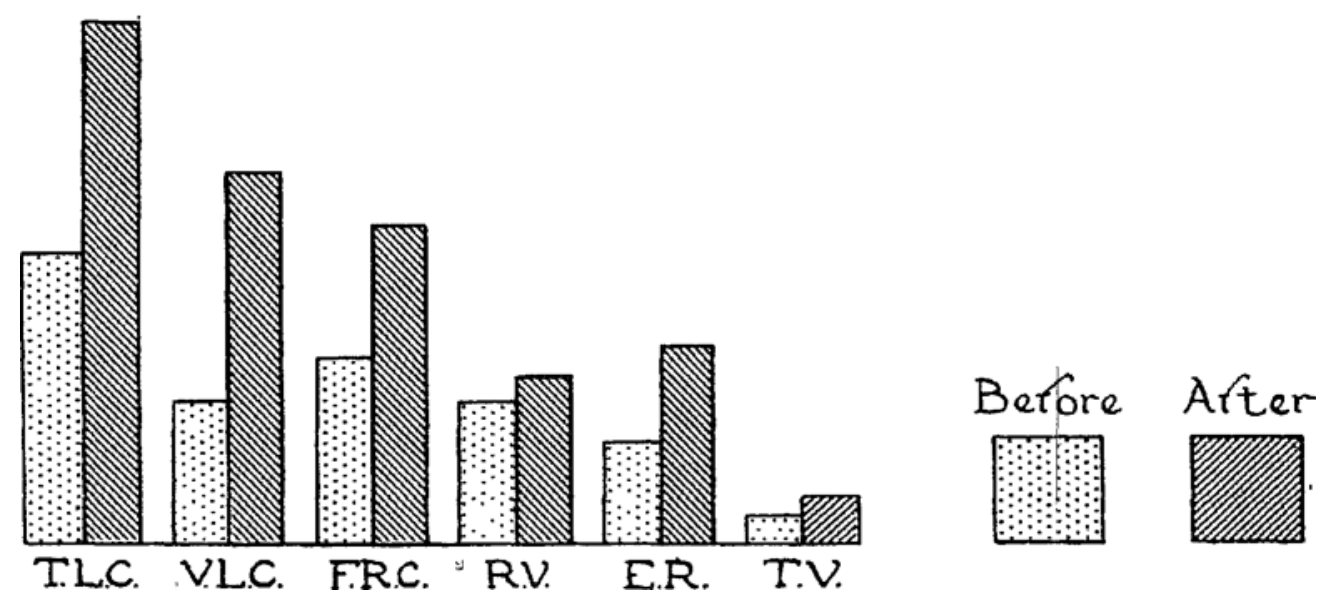

Figure 1. Improvement of lung volumes in one patient following loss in weight from 121.4 to $103.6 \mathrm{~kg}$. (from Burwell1), Cf. Table II.

TABLE II

Improvement in Lung Volumes (in litres) in One Patient Following LosS IN WEIGHT FroM $121 .+$ TO $103.6 \mathrm{~kg}$. (FROM BURWELL ${ }^{1}$ )

\begin{tabular}{lcc}
\hline & Before & After \\
\hline Total lung capacity & 3.3 & 6.0 \\
Vital lung capacity & 1.6 & 1.2 \\
Functional residual capacity & 2.1 & 3.6 \\
Residual volume & 1.6 & 1.8 \\
Expiratory reserve & 0.45 & 1.8 \\
Tidal volume & 0.31 & 0.36 \\
Minute volume & 6.0 & 7.3 \\
\hline
\end{tabular}

The exact mechanism responsible for shallow breathing in obesity is difficult to explain. However, the increased weight imposed by a thick chest wall is important. In addition, the elevated diaphragm encroaching on intrathoracic space decreases the expiratory reserve volume. The clinical implications of this will be illustrated in one of our cases. The resultant effect is a decrease in total lung capacity.

Butler and Arnott ${ }^{5}$ have demonstrated that as the lung approaches the expiratory position, the work of breathing increases. This would indicate that in obese patients, more work than normal will be required to maintain alveolar ventilation. Cherniak ${ }^{6,7,13}$ has confirmed this by showing that the mean oxygen cost of breathing, in terms of millilitres of oxygen consumed per litre of ventilation, was increased as much as three times in obese subjects. He also demonstrated an increase in respiratory effort at rest. This increased tremendously during periods of hyperventilation.

It also appears that in this condition ventilation may be affected by decreases in tidal volume. Figure 2 shows a definite increase in tidal volume with decrease in weight.

Hackney and his co-workers ${ }^{12}$ have recently demonstrated that intra-abdominal pressure-as evidenced by alterations in end-expiratory intragastric pressureis elevated in patients with the obesity-hypoventilation syndrome. It was consistently elevated when they were in the supine position and remained elevated when they sat up. They also noted increases in intra-abdominal pressures of 


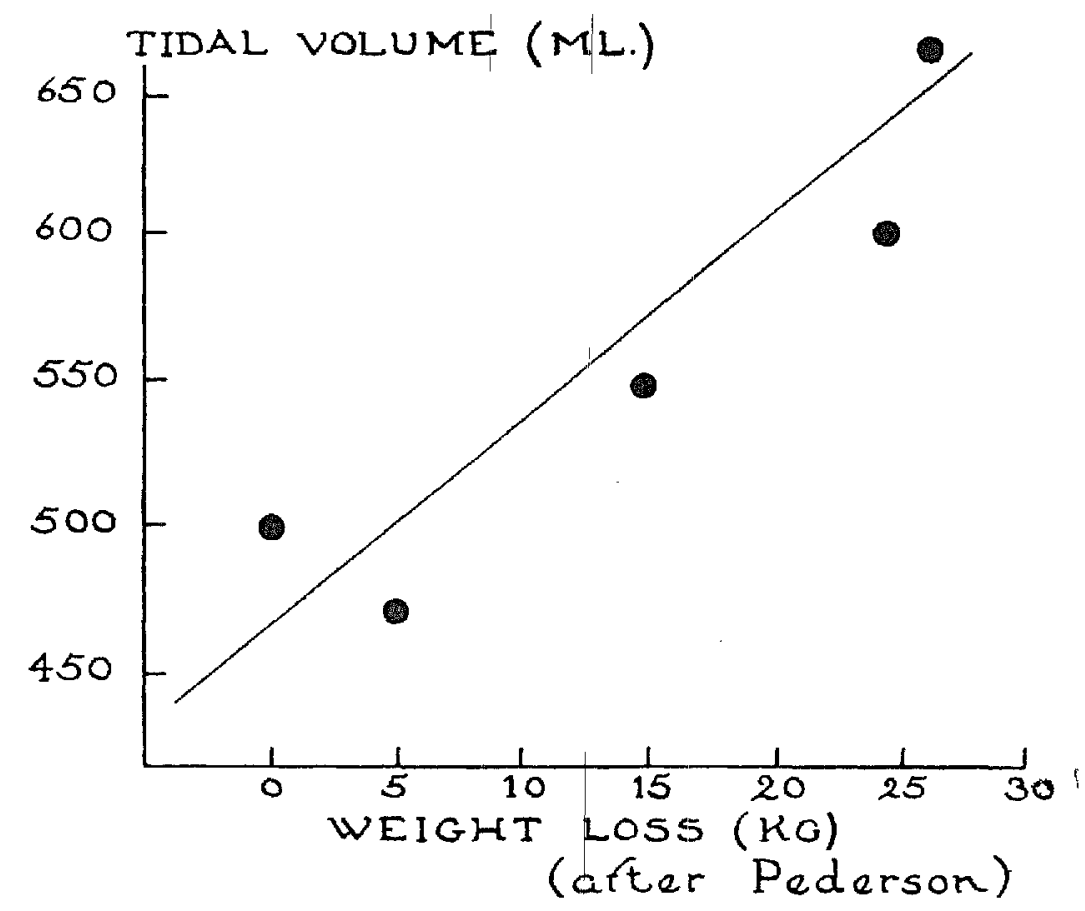

FIGURE 2

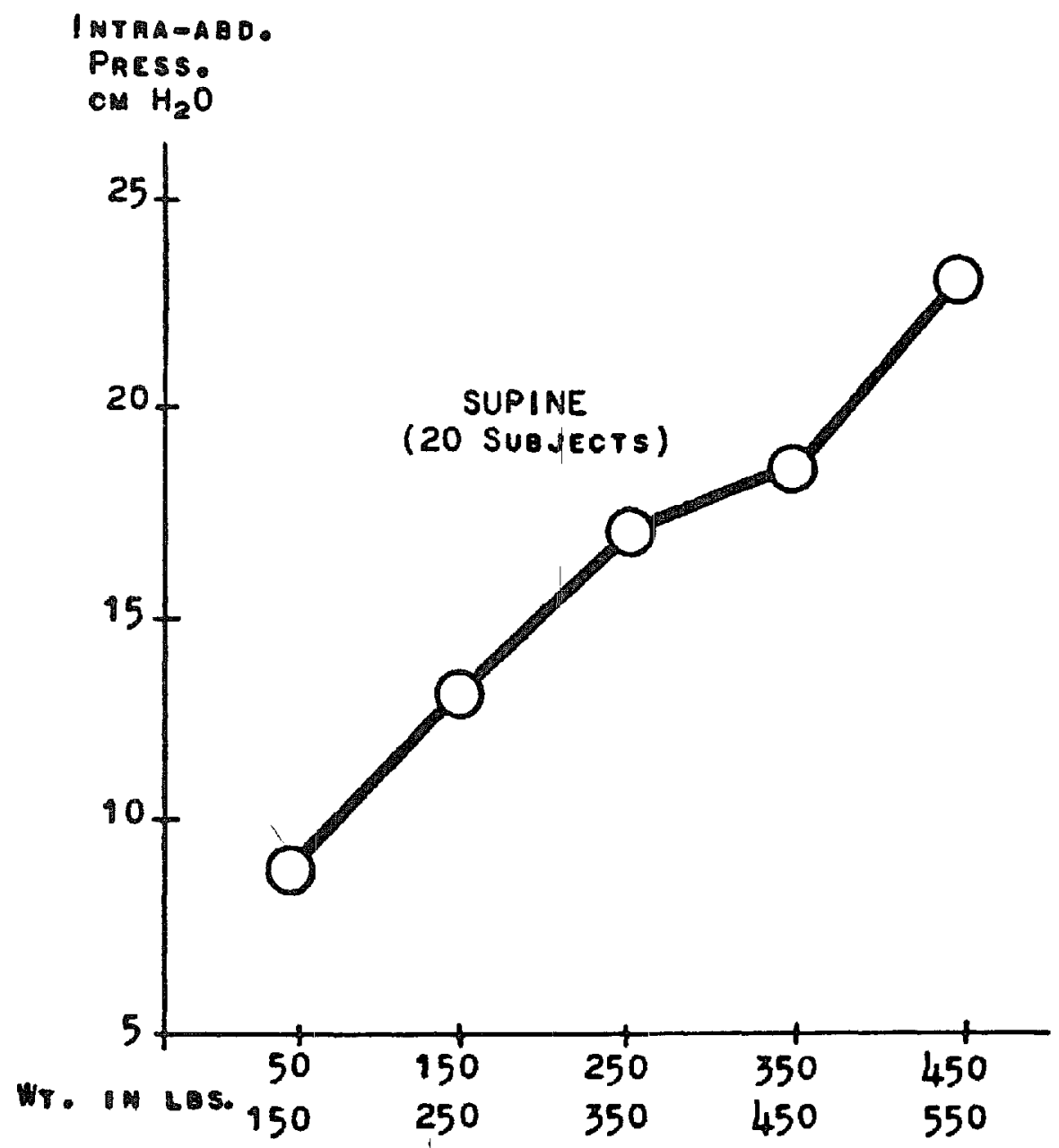

Figure 3. Relationship between intra-abdominal pressure in centimetres of water to weight in pounds (from Hackney ${ }^{12}$ ).

controls as weight increased. They conceded, however, that obese patients without hypoventilation might have elevated intra-abdominal pressures while supine that reverted to normal when they sat upright. (See Fig. 3.)

In Figure 4, the changes in intra-abdominal pressure during the respiratory cycle are shown for obese patients and normal people in the sitting position. In 


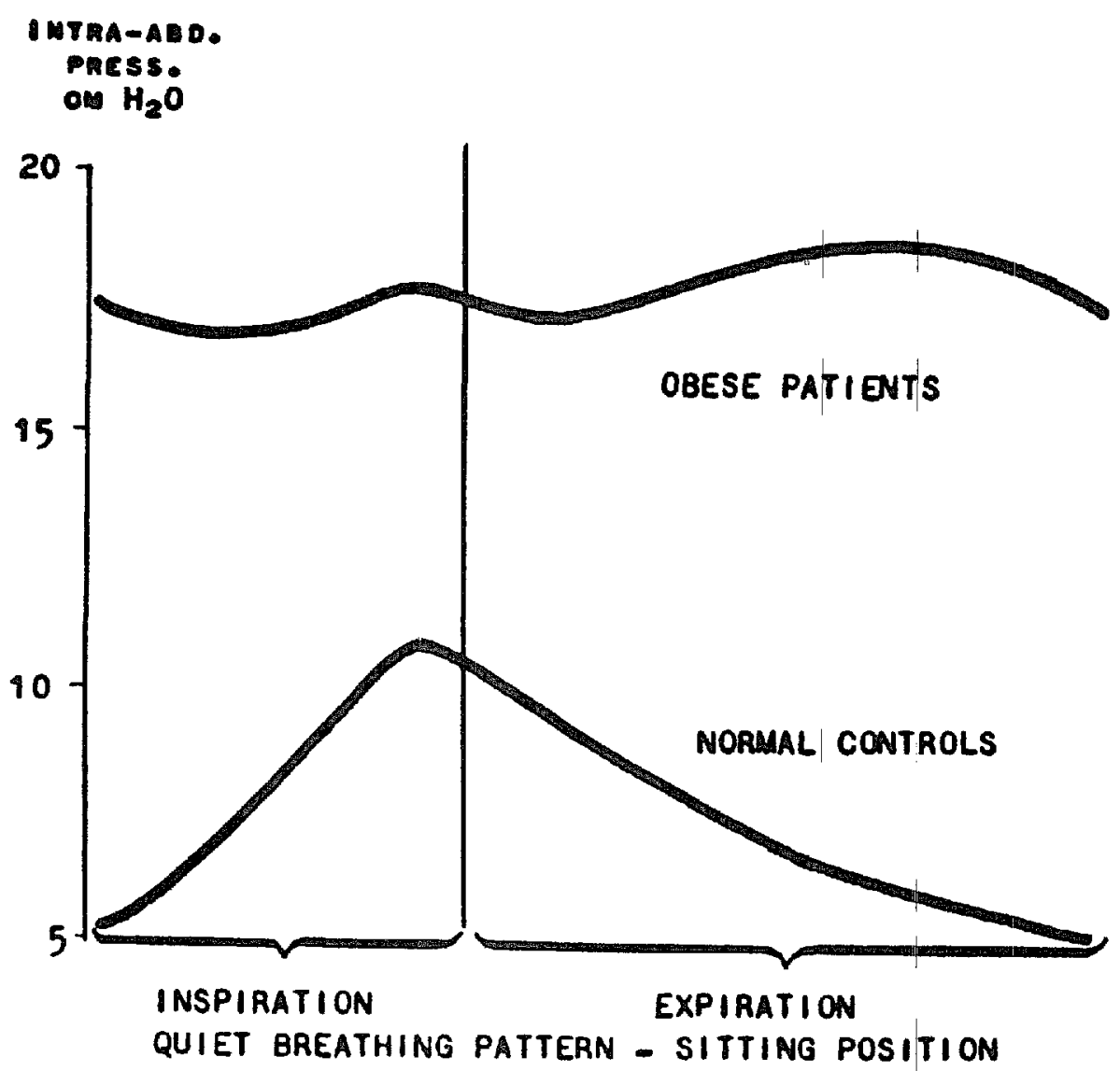

Figune 4. Changes in the pattern of intra-abdominal pressure during the respiratory cycle (from Hackney ${ }^{12}$ ).

the normals, there is an increase during inspiration with a decrease during expiration. Obese patients demonstrate a consistently higher pressure, with little change during inspiration and frequently an actual increase in pressure during expiration.

Hackney ${ }^{12}$ also calculated the average alterations in arterial $\mathrm{pCO}_{2}$ and oxygen saturation that occurred in four obese patients after a period of voluntary overbreathing lasting for 15 minutes. His results are as follows:

(1) Reduction in arterial $\mathrm{pCO}_{2}=62 \mathrm{~mm}$. $\mathrm{Hg}$ to $45 \mathrm{~mm}$. $\mathrm{Hg}$.

(2) Increase in $\mathrm{O}_{2}$ saturation $=76$ to 90 per cent.

It would appear that obesity can readily produce chronic hypoventilation.

Many will reasonably argue that we have not considered the potential compensating stimulus provided by the chemo-receptor mechanism. It is true that the retention of carbon dioxide may be the source of an additional stimulus. However, this reactive mechanism may become the victim of another obtunding effect in that the respiratory centre gradually loses its sensitive response to minor fluctuations in blood $\mathrm{pH}$. As a result a rise in $\mathrm{CO}_{2}$ tension is tolerated. A decreased response to $\mathrm{CO}_{2}$ inhalations has been noted in these patients.

The full-blown Pickwickian Syndrome is rare, and anaesthetists will seldom be confronted with it. This clinical description refers to the somnolence and respiratory centre depression resulting from hypoventilation. A resultant oxygen lack stimulates polycythemia and an increased blood volume, which increases respiratory effort. Pulmonary hypertension occurs and chronic cor pulmonale may terminate in right heart failure.

Obesity predisposes towards certain diseases and makes certain diseases worse. 
The increased work of carrying the load of fatty tissue adds to the strain of the patient with heart disease. A decrease in carbohydrate tolerance is common in this condition and life insurance statistics denote an increased morta'ity from hepatic cirrhosis in persons overweight at the time of issuance of their contracts. Zelman $^{11}$ surveyed 20 obese veterans and demonstrated a high incidence of impaired tolerance to glucose and abnormal retention of bromsulphthalein. Urinary urobilenogen, serum alkaline phosphatase, and cephalin cholesterol flocculations were abnormal in 20 to 30 per cent of the cases. Needle biopsies demonstrated abnormalities in 50 per cent of the subjects as evidenced by parenchymal degeneration, fatty change, periportal fibrosis, and bile-pigment retention.

The relation to hepatic function is interesting but the figures do not necessarily indicate a comparable reduction in ability to detoxify agents commonly used in anaesthesia. In dealing with these patients, we have no difficulty in selecting methods and agents that will be tolerated in the presence of even a moderate degree of liver dysfunction.

As we apply these considerations of obesity to anaesthesia, the effects on respiratory function predominate. With a simple Wright respiration meter we made certain measurements on a woman weighing 277 pounds. With a tidal volume of 360 millilitres, an alveolar ventilation of 3.99 litres per minute was found in the supine position, before operation. Under light general anaesthesia, with spontaneous breathing, this was reduced to 2.72 litres. The central depressant effects of premedicant and anaesthetic drugs, mechanical dead-space, and resistance are therefore considerable.

In a patient whose tidal volume is decreased by adiposity, the addition of mechanical dead-space may embarrass pulmonary ventilation because compensation by an increase in respiratory rate is effective up to a certain degree only: The increased effort of breathing may be aggravated by the resistance in modern machines, particularly the circle filter, if reliance is placed on spontaneous breathing.

We can go further and postulate that most very obese patients will hypoventilate under inhalation anaesthesia if they are allowed to breathe spontaneously despite the reductions of dead-space afforded by endotracheal intubation. In addition, many of the centrally depressant combinations of narcotics and barbiturates not only depress respiration, but also the respiratory response to hypercapnia.

It is difficult to assess the degree of obesity that is necessary to impose these problems related to inhalation anaesthesia. However, the preoperative assessment of these patients with a simple respiration meter is simple and helpful.

\section{The Use of Relaxants}

We have all noted abnormalities in the response of fat patients to relaxants. Assisted ventilation may be less efficient as a result of decreased compliance of the chest and increased intra-abdominal pressure. A tachypnoea develops in the presence of increased effort.

Under these circumstances controlled respiration under the influence of a relaxant drug is naturally more efficient. But when the time arrives to establish 
the return of spontaneous ventilation, we have more problems than merely a depressed respiratory centre and a possible respiratory alkalosis from hyperventilation. We also have a situation in which weakened muscles are struggling to produce the increased effort required for spontaneous breathing. Because of this residual myasthenia, adequate respirations may not be restored for some time.

Obese patients are often the recipients of an overdose of relaxant. An effective dose will often produce an apparently inadequate effect. This is due to the visceral protrusion resulting from the increased intra-abdominal pressure and the increased volume of intra-abdominal fat. It will be exaggerated if the intestinal tract is distended. The surgeon demands more relaxation and the patient too often receives more relaxant. The demand is repeated as he attempts to replace the voluminous abdominal contents. The hazard applies particularly to the use of a continuous infusion of succinylcholine. The mechanical problems presented by obesity increase the difficulty of titrating the infusion to the patient's responses. Not only the inexperienced err by giving too much. As amounts of succinylcholine used exceed 1 gram, monocholine effects or a dual block may result. There is less hazard in the administration of divided doses. In this way the total dosage can be materially reduced.

\section{Case 1}

Our indiscretions in the management of this obese patient will be readily identified. She weighed 277 pounds. Admitted to hospital for gynaecological investigation, which was negative, she requested that her large ventral hernia be repaired before leaving. This was done immediately, and under general anaesthesia a large amount of omental fat was replaced inside the abdominal cavity and the hernia repaired. Adequate relaxation appeared difficult during surgery, and a total of 1.6 grams of succinylcholine was administered in a 0.1 per cent infusion over a $2 \%$-hour period. Respirations were delayed postoperatively, and respiratory inadequacy was apparent for some time. When it was considered that respirations were adequate, the patient was removed to the recovery room. No spirometric readings were taken at this time. Rapid, laboured, shallow respirations soon became obvious, her colour deteriorated, and secretions began to accumulate. A tracheotomy was performed and respirations supported mechanically. She was on continuous respiratory control for seven days, with periodic assistance for another five days, before adequate spontaneous ventilation was possible without fatigue.

This unfortunate occurrence resulted in a patient when elective abdominal surgery was attempted without insistence on preoperative reduction in weight. A large volume of intestines and fat, previously free, was suddenly confined in the abdomen under tension. Respirations were embarrassed postoperatively by the residual effects of a large dose of relaxant, combined with the depressant effects of opiates, and postoperative pain with muscle splinting:

\section{Conduction ANaesthesia}

Let us contrast the operating conditions afforded by conduction methods. A maximum relaxant effect can be localized to the lọwer thoracic and lumbar 
segments without resultant diaphragmatic weakness. The degree of impairment of intercostal function can be skilfully controlled and compensation by assistance or controlled methods is easy. Some years ago, Dr. Bromage was able to demonstrate in our department that under epidural anaesthesia and with the patient intubated, complete manual or automatic control of breathing is readily acquired despite the persistence of an active phrenic reflex. We hope to be able to confirm the impression that the increases in intra-abdominal pressure are relatively decreased under conduction methods as compared with inhalation techniques: Nevertheless, with properly controlled conduction methods, postoperative hypoventilation is not as common. In addition, with the continuous administration of weak solutions, postoperative pain can be well controlled without having to resort to the depressant effects of narcotics.

\section{Case 2}

This fat man had a superimposed steroid-induced obesity. Because his arthritis subsided and he felt better, he ignored his doctor and increased his Metacortin intake to 15 milligrams daily for several months. He developed a gastric haemorrhage, which continued for five days in the local hospital, but he was transfused regularly. The local hospital staff were particularly concerned about the anaesthetic risk. We operated on him under spinal anaesthesia a few hours after transfer. Pontocaine-20 milligrams with glucose-was given with the patient upright and a resulting sensory level to $\mathrm{T}_{2}$ was obtained. He remained awake most of the time, received supplemental oxygen, and his tidal exchange was obviously adequate. Because of a productive bronchitis, postoperative tracheatomy was performed.

The anticipated delay in wound healing occurred and dehiscence occurred on the ninth day. Intratracheal administration of cyclopropane and a single dose of 60 milligrams of succinylcholine with controlled respirations were adequate for the second procedure. Spinal anaesthesia was contraindicated at the time because of considerable intra-abdominal haemorrhage and signs of incipient shook.

\section{Case 3}

This patient weighed 340 pounds and presented with definite hypoventilation. Twenty years ago she weighed 120 pounds and at that time she was diagnosed as an epileptic because of periodic attacks of confusion terminating in convulsions. She had very casual medical treatment, and soon learned that orange ,juice, well sweetened, would often abort these attacks. During the past twenty years she has consumed daily sixty ounces of orange juice sweetened with one pound of glucose. Hence her obesity. After admission to our hospital, glucose curves revealed decreases to 12 milligrams per cent without unconsciousness, and on one occasion a level of 1.5 milligrams per cent was recorded. A diagnosis of islet cell tumour of the pancreas was made and the anaesthetic problems presented to us. Adequate abdominal relaxation had to be provided without further impairment of ventilation. Postoperative ventilation had to be adequate.

A continuous epidural anaesthetic was given through a catheter inserted between $T_{12}$ and $L_{1}$. With 20 c.c. of 2 per cent Xylocaine an anaesthetic level to 
$\mathrm{T}_{2}$ was obtained. The patient was then intubated with difficulty after administration of pentothal, nitrous oxide, succinylcholine, and a topical spray of the vestibule. Controlled respirations were continued mânually. Initial bronçhospasm was controlled by adding about 1 per cent Fluothane. Through a transverse abdominal incision, a small tumour of the pancreas was easily found and removed. Postoperatively, spontaneous respirations returned quickly. These were monitored with a meter. When adequate spontaneous breathing had been resumed after half an hour, an elective tracheotomy was performed with considerable difficulty and a James tube inserted. The ordinary metal Mörch tubes could not be inserted because of the deep fat in the neck. The patient did well, but two hours postoperatively, despite an apparently adequate respiratory yolume, her end-expiratory $\mathrm{CO}_{2}$ tension was found to be 57 millimetres of mercury. However, an arterial sample taken at the same time gave a reading of only 46 millimetres of mercury. The end-expiratory sample had obviously given a false reading because of the continuing elimination of nitrous oxide, to which the infra-red $\mathrm{CO}_{2}$ analyzer is sensitive.

TABLE III

Respiratory Data for Case 3 (age 57, weight 340 pounds)

\begin{tabular}{lcccc}
\hline & $\begin{array}{c}\text { Preop., } \\
\text { sitting }\end{array}$ & $\begin{array}{c}\text { Preop., } \\
\text { supine }\end{array}$ & $\begin{array}{r}\text { Postop. (pain), } \\
\text { supine-trach. }\end{array}$ & $\begin{array}{c}\text { Postop., } \\
\text { 24 hours }\end{array}$ \\
\hline Inspiratory capacity & 1.61 & 1.65 & 1.10 & - \\
Expiratory reserve volume & 0.05 & 0.06 & 0.04 & - \\
Vital capacity & 1.66 & 0.60 & 1.41 & - \\
Total lung capacity & 2.84 & 2.81 & 1.97 & - \\
Mixing effiency, \% & 46 & - & 7.433 & 7.435 \\
Arterial pH & 7.43 & - & 46 & 45 \\
pCO & 52 & - & 86 & 90 \\
Saturation, \% & 93 & - & 29 & 29.5 \\
Bicarbonate, mm./L. & 32 & 520 & 400 & - \\
$\mathrm{O}_{2}$ uptake, c.c. & & & &
\end{tabular}

Table III illustrates some aspects of this patient's respiratory insufficiency. You will note particularly a marked reduction in her expiratory reserve volume, denoting a definite decrease in cough potential.

This patient required no post-operative respiratory assistance and her tracheotomy was closed on the ninth day. Recovery was uneventful.

\section{SUMMARY}

The physiological changes responsible for the syndrome of hypoventilation in obesity are discussed. This state may be intensified during anaesthesia for abdominal surgery, and an obese person not suffering from hypoventilation may readily develop this condition when anaesthetized. Further studies are in order to establish more clearly the effects of various types of anaesthesia on the altered lung volumes and mechanics of respiration occurring in fat people. It is proposed that relaxant drugs are hazardous. It is, our unconfirmed opinion that spinal and epidural anaesthesia allow establishment of adequate respiratory control, with a decreased hazard of immediate postopérative respiratory insufficiency. 


\section{REFERENCES}

1. Burwell, C. S., Rubin, E. D.; Whaley, R. D.; \& Bickelmann, A. G. Extreme Obesity Associated with Alveolar Hypoventilation. Am. J. Med. 21: 811-19 (1956).

2. Carroll, D. Cardiopulmonary Failure Associated with Obesity. Am. J. Med. 21: 819-24 (1956).

3. Seme, M. J. Heart Failure due to Extreme Obesity. New England J. Med. 25: 1227-30 (1957).

4. Fairley, H. B., \& Chambers, R. A. The Management of the Patient/ with Respiratory Insufficiency. Canad. Anaes. Soc. J. 7: 447-95 (1960).

5. Butler, J., \& Arnotr, W. M. The Work of Pulmonary Ventilation at Different Respiratory Levels. Clin. Sci. 14: 703 (1955).

6. Cherniak, Reuben. Respiratory Effects of Obesity. Canad. M.A.J. 80: 613 (1959).

7. Kaufman, B. J.; Ferguson, M. H.; \& Cherniax, R. M. Hypoventilation in Obesity. J. Clin. Investigation 38: 500 (1959).

8. Pedersen, J., \& Torp-Pedersen, E. Ventilatory Insufficiency in Extreme Obesity. Acta Med. Scand. 167: 343 (1960).

9. Fishman, A. P.; Turino, G. N.; Bercof\$kx, E. H. The Syndrome Hypoventilation. Am. J. Med. 23: 333 (1957).

10. Alexander, J. K.; Armad, K. H.; \& Colr, W. Further Studies on the Cardio-pulmonary Effects of Extreme Obesity. J. Lab, \& Clin. Med. 56: 787 (1960).

11. Zelman, S. The Liver in Obesity. A.M.A. Arch. Int. Med. 90: 141 (1952).

12. Hackney, J. D.; Crane, M. G.; Collier, C. C.; Rokaw, S.; \& Greiggs, D. E. Syndrome of Obesity and Hypoventilation: Studies of Etiology. Ann. Int. Med. 51: 541 (1959).

13. Kaufman, B. J.; Ferguson, M. H.; \& Cherniak, R. M. Hypoventilation in Obesity. J. Clin. Investigation 38: 3 (1959).

14. EckenhofF, J. E., \& Helrich, M. The Effect of Narcotics, Thiopental and Nitrous Oxide upon Respiration and Respiratory Response to Hypercarbia. Anesthesiology 19: 240-52 (1958).

15. Earue, R. H.; Perkins, J. F.; \& Adams, W. E. Carbon Dioxide Retention during Hypoventilation. Anesthesiology 19: 153-63 (1958). 